\title{
Formulation and Evaluation of Floating Tablets of Tofacitinib Citrate
}

\author{
Sanjeshkumar G. Rathi*, Jaykumar G. Chaudhari, Sohansinh S.Vaghela, Kaushik R Kamani, Maulikkumar D. Vaja
}

Department of Pharmaceutics, Saraswati Institute of Pharmaceutical Sciences, Dhanap. Gandinagar-382355, Gujarat, India.

*Corresponding author's E-mail: rathi.sanjesh@gmail.com

Received: 15-04-2021; Revised: 19-06-2021; Accepted: 26-06-2021; Published on: 15-07-2021.

\section{ABSTRACT}

The present research work done with an objective of preparation and evaluation of floating tablets of Tofacitinib Citrate drug with Hydroxy propylene methyl cellulose (HPMC), Polyox N-60K, Carbopol 934 P and Guar gum polymers. Floating tablets were based on effervescent approach using sodium bicarbonate a gas releasing agent. Direct compression method was used in present study for preparation of tablets. Effect of polymers was evaluated by studying drug release and floating time. In-vitro drug release profile indicates that sustained nature increased by increasing the concentration of polymer. The formulation containing Polyox N-60K and Carbopol $934 \mathrm{P}$ in combination was optimized as it showed drug release up to $12 \mathrm{hrs}$. Optimized formulation F18 was found stable during stability condition up to 1 month.

Keywords: Tofacitinib Citrate, Floating Tablets, Carbopol 934 P.

QUICK RESPONSE CODE $\rightarrow$

DOI:

10.47583/ijpsrr.2021.v69i01.025

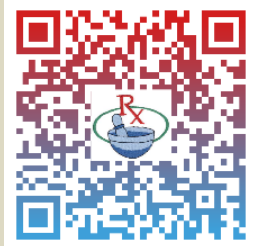

DOI link: http://dx.doi.org/10.47583/ijpsrr.2021.v69i01.025

\section{INTRODUCTION}

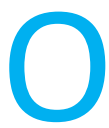

ral route of administration is the most important and convenient route for drug delivery. Due to differential absorption from various regions of GIT, the benefits of long-term delivery technology have not been fully realized for dosage forms designed for oral administration. Only few drug delivery systems have been designed to target drugs to differential regions of GIT. These include gastro retentive systems, delayed release systems and colon targeting. ${ }^{1}$ The real issue in the development of oral controlled release dosage form is not just to prolong the delivery of drugs for more than $12 \mathrm{~h}$ but also to prolong the presence of dosage forms in the stomach or somewhere in the upper small intestine. Dosage forms with prolonged gastric residence time (GRT), i.e. gastro remaining or gastro retentive dosage form (GRDF), will bring about new and important therapeutic options. ${ }^{1}$

\section{Approaches for Gastric Retention ${ }^{2}$}

\section{Floating System (Low Density Approach)}

These systems are also known as hydro dynamically balanced systems. (HBS/FDDS) They have a bulk density lower than gastric fluid (i.e. $<1.004 \mathrm{gm} / \mathrm{ml}$ )

The specific gravity of gastric fluid is approximately 1.004$1.010 \mathrm{~g} / \mathrm{cm}^{3}$ according to the "Documenta Geigy" and thus the FDDS remains buoyant in the stomach without affecting the gastric emptying rate for a prolonged period of time.

It is an oral dosage form (capsule or tablet) that is designed to prolong the residence time of the dosage form within the Gl tract.

\section{Design and Fabrication of FDDS ${ }^{3,4}$}

\section{Non effervescent FDDS}

\section{Colloidal gel barrier systems}

Hydro dynamically balanced system ( $\mathrm{HBS}^{\mathrm{TM}}$ ) of this type contains drug with gel forming or swellable cellulose type hydrocolloids, polysaccharides and matrix forming polymers. These systems incorporate high levels (20 to 75 $\% \mathrm{w} / \mathrm{w}$ ) of one or more gel forming highly swellable cellulose type hydrocolloids for e.g. hydroxyl ethyl cellulose (HEC), hydroxyl propyl cellulose (HPC), hydroxyl propyl methyl cellulose (HPMC), sodium carboxy methyl cellulose ( $\mathrm{NaCMC})$, polysaccharides and matrix forming polymers such as poly-carbophill, poly-acrylates and polystyrene incorporated either in tablets or capsules. When such a system comes in contact with the gastric fluid, the hydrochloride in the system hydrates and forms a colloidal gel barrier around its surface. This gel barrier controls the rate of the fluid penetration into the device and consequent release of drug from it.

\section{Micro porous compartment system ${ }^{5,6,7}$}

This technology is comprised of encapsulation of a drug reservoir inside a micro porous compartment with pores along its top and bottom surfaces. The peripheral walls of the drug reservoir compartment are completely sealed to prevent any direct contact of gastric mucosal surface with un-dissolved drug. 
In stomach, the floatation chamber containing entrapped air causes the delivery system to float over the gastric contents. Gastric fluid enters through the pores, dissolves the drug and carries the dissolved drug for continuous transport across the intestine for absorption.

\section{Alginate beads}

Multiple unit floating dosage forms have been developed from freeze-dried calcium alginate. Spherical beads of approximately $2.5 \mathrm{~mm}$ in diameter were prepared by dropping a sodium alginate solution into aqueous solution of calcium chloride, causing a precipitation of calcium alginate. These beads were then separated; snap frozen in liquid nitrogen and freeze dried at $-40{ }^{\circ} \mathrm{C}$ for $24 \mathrm{~h}$, leading to formation of porous system that maintained floating force for over $12 \mathrm{~h}$.

\section{Hollow microspheres}

Hollow microspheres (micro balloons), loaded with ibuprofen in their outer polymer shells were prepared by novel emulsion solvent diffusion method. The ethanol: dichloromethane solution of the drug and an enteric acrylic polymer were poured into an agitated aqueous solution of PVA that was thermally controlled at $40^{\circ} \mathrm{C}$. The gas phase was generated in dispersed polymer droplet by evaporation of dichloromethane and formed an internal cavity in microspheres of polymer with drug.

\section{Effervescent systems}

A drug delivery system can be made to float in the stomach by incorporating a floating chamber, which may be filled with vacuum, air or inert gas. The gas in floating chamber can be introduced either by volatilization of an organic solvent or by effervescent reaction between organic acids and bicarbonate salts.

\section{Volatile liquid containing systems}

The GRT of a drug delivery system can be sustained by incorporating an inflatable chamber which contains a liquid e.g. Ether or Cyclo-pentane that gasifies at body temperature to cause the inflation of the chamber in the stomach. These devices are osmotically controlled floating systems containing a hollow deformable unit that can be converted from a collapsed to an expanded position and returned to collapse position after an extended period.

\section{Gas generating systems}

These buoyant delivery systems utilize effervescent reaction between carbonate/bicarbonate salts and citric/tartaric acid to liberate $\mathrm{CO}_{2}$ which gets entrapped in the jellified hydrochloride layer of the system, thus decreasing its specific gravity and making it float over chyme.

\section{MATERIALS}

Tofacitinib Citrate received as gift sample from Zydus Research Centre, Ahmedabad, Lactose, HPMC K4M, HPMC K15M, HPMC K100M, Carbopol 934, Sodium bicarbonate Citric Acid, Sodium bicarbonate Citric Acid, PVP K30, Talc, Magnesium Stearate and Polyox N-604 purchase from the ACS Chemicals, Ahmedabad. Polyox N-604 received as gift sample from Colorcon Asia Pvt. Limited.

\section{METHODS $^{9}$}

\section{Pre-Formulation Studies}

\section{Characterization of API}

\section{Organoleptic Characteristics}

Colour, odour \& Appearance of Tofacitinib were characterized and recorded using descriptive terminology.

\section{Flow Properties}

\section{Bulk density and tapped density}

An accurately weighed quantity of the Drug (W), was carefully poured into the $10 \mathrm{ml}$ graduated cylinder and the volume $\left(V_{0}\right)$ was measured. Then the graduated cylinder was tap for 100 times and after that the volume $\left(V_{f}\right)$ was measured which was tapped volume. The bulk density and tapped density were calculated by using the following formulas.

$$
\text { Bulk density }=\mathrm{W} / \mathrm{V}_{0} \text { Tapped density }=\mathrm{W} / \mathrm{V}_{\mathrm{f}}
$$

\section{Compressibility index $(\mathrm{Cl})$ / Carr's index}

It was obtained from bulk and tapped densities. It was calculated by using the following formula.

$$
\begin{gathered}
\% \text { Carr's index }=(\text { Tapped Density }- \text { Bulk Density } \div \text { Tapped } \\
\text { Density }) \times 100
\end{gathered}
$$

\section{Hausner's ratio}

Hausner's ratio is a number that is correlated to the flow ability of a powder. It is measured by ratio of tapped density to bulk density.

$$
\text { Hausner's ratio }=(\text { Tapped density } \div \text { Bulk Density })
$$

\section{Angle of repose}

Angle of repose of powder was determined by the funnel method. Accurately weight powder blend was taken in the funnel. Height of the funnel was adjusted in such a way the tip of the funnel just touched the apex of the powder blend. Powder blend was allowed to flow through the funnel freely on to the surface. Diameter of the powder cone was measured and angle of repose was calculated using the following equation.

$$
\operatorname{Tan} \theta=h / r
$$

\section{Preparation of Floating Tablets of Tofacitinib Citrate}

\section{Dose Calculation for Sustained Release dosage form}

The total dose of Tofacitinib Citrate for a sustained release formulation was calculated by following four equations 
using available pharmacokinetic data from a design of one compartment model with simultaneous release of loading dose and a zero order release maintenance dose, as described by Robison and Eriksen.

$$
\begin{aligned}
& \mathrm{k}_{0}=\text { Dike (1) } \\
& \mathrm{D}_{\mathrm{m}}=\mathrm{k} 0 \mathrm{~T}(2) \\
& \mathrm{D}_{\mathrm{l}}=\mathrm{Di}-\mathrm{k} 0 T \mathrm{Tp}(3) \\
& \mathrm{D}_{\mathrm{t}}=\mathrm{DI}+\mathrm{Dm}(4)
\end{aligned}
$$

Where, $\mathrm{k} 0=$ zero order drug release.

$$
\begin{aligned}
& \mathrm{ke}=0.693 / \mathrm{t}_{1 / 2} \\
& \mathrm{Di}=\text { initial dose/conventional dose } . \\
& \mathrm{DI}=\text { loading dose } \\
& \mathrm{Dm}=\text { maintenance dose } \\
& \mathrm{T}=\text { time for sustained action } \\
& \mathrm{Tp}=\text { time to reach peak plasma concentration } \\
& \mathrm{Dt}=\text { total dose of drug. } \\
& \mathrm{k} 0=\mathrm{Dike}=5 \times 0.693 / 3=1.155 \mathrm{mg}(5) \\
& \mathrm{Dm}=\mathrm{k} 0 \mathrm{~T}=1.155 \times 12=13.860 \mathrm{mg}(6) \\
& \mathrm{DI}=\mathrm{Di}-\mathrm{k} 0 \mathrm{Tp}=5-(1.155 \times 1)=3.845 \mathrm{mg}(7) \\
& \mathrm{Dt}=\mathrm{DI}+\mathrm{Dm}=3.845+13.860=17.705 \mathrm{mg}(8)
\end{aligned}
$$

$8.08 \mathrm{mg}$ of Tofacitinib Citrate is equivalent to $5.0 \mathrm{mg}$ of Tofacitinib, So for 17.705 Tofacitinib, $28.611 \mathrm{mg}$ Tofacitinib Citrate is required. Hence the tablet should contain a total dose of $28.6 \mathrm{mg}$ for $12 \mathrm{hrs}$. sustained release dosage form and it should release $5 \mathrm{mg}$ initial dose in 1st hour like conventional dosage form and remaining dose will be release in remaining 11 hours, Hence, the theoretical drug release profile can be generated using above value, which is shown in below table.

\section{Evaluation of Floating Tablets}

\section{Weight variation test}

Weight variation test was performed by taking 20 tablets of each batch and weighed using a balance. The average weight and standard deviation were recorded.

\section{Hardness}

The hardness of three tablets was determined using the Monsanto hardness tester and the average values were calculated.

\section{Thickness}

The thickness of the tables was determined by using digital Vernier calipers. Three tablets were used, and average values were calculated.

\section{Tablet friability}

The friability of the tablets was measured in a Roche Friabilator. Tablets of a known weight $\left(\mathrm{W}_{0}\right)$ or a sample of 10 tablets are dedusted in a drum for a fixed time (100 revolutions) and weighed (W) again. Percentage friability was calculated from the loss in weight as given in equation as below. The weight loss should not be more than $1 \%$. Determination was made in triplicate.

$$
\% \text { Friability }=\frac{W_{0}-W}{W_{0}} \times 100
$$

\section{Drug content}

Ten tablets were weighed individually, and the drug was extracted in $0.1 \mathrm{~N} \mathrm{HCl}$, filter through $0.45 \mu$ membrane. The absorbance was measured at $287 \mathrm{~nm}$ after suitable dilution using a Shimadzu UV-1700 UV/Vis double beam spectrophotometer.

\section{In vitro buoyancy studies}

The in vitro buoyancy was determined by using dissolution testing apparatus USP type-II.The tablets were placed in $900 \mathrm{ml} 0.1 \mathrm{~N} \mathrm{HCL}$ at $100 \mathrm{rpm}$ basket rotation at $37 \pm 0.5$ 으. The time require for tablets to ascend to the surface of dissolution medium and time taken by tablet to buoyant on surface of medium was recorded as floating lag time and total floating time.

\section{Swelling index}

The swelling index of tablets was in $0.1 \mathrm{~N} \mathrm{HCL}$. Tablets were weighed individually named as $W_{0}$ and then it is placed in separately in glass beaker containing $200 \mathrm{ml} 0.1 \mathrm{~N} \mathrm{HCL}$ at $37 \pm 0.5 \circ C$. At periodical time interval tablets were removed from beaker and extra amount of surface water discarded by blotting paper and then tablets were weighed and it is referred as $W_{t}$ and swelling index was calculated using following formula:

Swelling index $=\frac{W_{t}-W_{0}}{W_{0}}$

Where

$\mathrm{W}_{\mathrm{t}}=$ weight after swelling

$\mathrm{W}_{0}=$ weight before swelling

Where, $W_{0}$ is the initial weight of tablet, and $W_{t}$ is the weight of the tablet at time $t$.

\section{In Vitro Dissolution Studies}

USP apparatus II was used to test the dissolution profile using $900 \mathrm{ml}$ of $0.1 \mathrm{~N} \mathrm{HCl}$ as dissolution medium at $50 \mathrm{rpm}$ and $37^{\circ} \mathrm{C} \pm 0.5^{\circ} \mathrm{C}$. Six tablets from each batch were placed into respective basket containing $\mathrm{HCl} .5 \mathrm{ml}$ of the sample was withdrawn hourly for $12 \mathrm{hrs}$. The sample was filtered and from the filtrate $3 \mathrm{ml}$ was withdrawn. The volume was adjusted to $100 \mathrm{ml}$ with $0.1 \mathrm{~N} \mathrm{HCl}$. Absorbance of the solution was measured using UV spectrophotometer at $287 \mathrm{~nm}$

\section{Drug Release Kinetic Study}

Data obtained form in vitro drug release studies were fitted to Disso calculation software. The kinetic models 
used are zero order, first order, Korshmers and papps, Hexoncrowell, and Higuchi equation.

The rate and mechanism of release of drug from the prepared tablets were analyzed by fitting the dissolution data into the zero-order equation:

$$
\mathrm{Q}=\mathrm{kot}
$$

Where, $Q$ is the amount of drug released at time $t, k 0$ is the release rate constant. The dissolution data fitted to the first order equation:

$$
\ln (100-Q)=\ln 100-K_{1} t
$$

Where, $\mathrm{k} 1$ is the release rate constant. The dissolution data was fitted to the Higuchi's equation:

$$
\mathrm{Q}=\mathrm{k}_{2} \mathrm{t}_{1 / 2}
$$

Where, $\mathrm{k} 2$ is the diffusion rate constant.

The dissolution data was also fitted to Korsmeyer equation, which is often used to describe the drug release behavior from polymeric systems:

$$
\log (M t / M \infty)=\log k+n \log t
$$

Where $\mathrm{Mt}$ is the amount of drug released at time $\mathrm{t}, \mathrm{M} \infty$ is the amount of drug release after infinite time, $K$ is a release rate constant incorporating structural and geometric characteristics of the tablet, $\mathrm{n}$ is the diffusion exponent indicative of the mechanism of drug release.

\section{Stability Study}

Optimized Batch of prepared floating tablet subjected to accelerated stability studies at $40{ }^{\circ} \mathrm{C}$ and $75 \% \mathrm{RH}$ for 1 month in a humidity chamber. The tablets of best batch were packed in aluminum foil pouch and analyzed for Assay, floating behavior and in-vitro drug release study.

\section{RESULTS \& DISCUSSION}

\section{Pre-formulation Studies}

Based on results, it concluded that the API has a poor flow in nature. Hence, it is required to use directly compression grade material which has granular material itself. For this purpose, lactose DCL 11 grade was selected. The proposed formulation was gastro retentive dosage form targeted for $12 \mathrm{hrs}$ so the solubility of API in $0.1 \mathrm{~N} \mathrm{HCl}$ checked. The API was found soluble in the acidic medium. Hence, solubility enhancement not required.

\section{Evaluation of Formulation F1-F19 of Tofacitinib Citrate Floating Tablets}

\section{Pre-Compression Parameters Evaluation}

Powder blend of formulation F1-F19 checked for pre compression parameters like,

Bulk density, Tapped density, Compressibility index (Cl) / Carr's index, Hausner's ratio and angle of repose Observed results are mentioned in following table 1 . From the below table 1 , it is observed that bulk density found between $0.43-0.55 \mathrm{~g} / \mathrm{ml}$ and tapped density found between 0.50 $0.62 \mathrm{~g} / \mathrm{ml}$. Hausner's ratio value is less than 1.25 for all formulation means all the formulation has good flow properties. And it favors to do with direct compression method for tablet preparation.

Table 1: Pre-Compression Parameters of Formulation F1-F19

\begin{tabular}{|c|c|c|c|c|c|}
\hline Formulation & $\begin{array}{c}\text { Bulk density } \\
\mathbf{( g / m l )}(\mathbf{n}=\mathbf{3})\end{array}$ & $\begin{array}{c}\text { Tapped density } \\
\mathbf{( g / m l )}(\mathbf{n}=\mathbf{3})\end{array}$ & $\begin{array}{c}\text { Carr's index }(\mathbf{\%}) \\
\mathbf{( n = 3 )}\end{array}$ & $\begin{array}{c}\text { Hausner's ratio } \\
(\mathbf{n}=\mathbf{3})\end{array}$ & $\begin{array}{c}\text { Angle of repose } \\
\mathbf{( \boldsymbol { \theta } ^ { \circ } )} \mathbf{( n = 3 )}\end{array}$ \\
\hline F1 & $0.54 \pm 0.02$ & $0.61 \pm 0.03$ & $11.48 \pm 0.01$ & $1.13 \pm 0.02$ & $17.25 \pm 0.05$ \\
\hline F2 & $0.48 \pm 0.03$ & $0.52 \pm 0.05$ & $7.69 \pm 0.02$ & $1.08 \pm 0.01$ & $19.22 \pm 0.08$ \\
\hline F3 & $0.47 \pm 0.05$ & $0.55 \pm 0.03$ & $14.55 \pm 0.04$ & $1.17 \pm 0.02$ & $21.12 \pm 0.07$ \\
\hline F4 & $0.57 \pm 0.07$ & $0.60 \pm 0.04$ & $5.00 \pm 0.07$ & $1.05 \pm 0.01$ & $19.26 \pm 0.08$ \\
\hline F5 & $0.47 \pm 0.04$ & $0.54 \pm 0.04$ & $12.96 \pm 0.05$ & $1.15 \pm 0.02$ & $25.15 \pm 0.07$ \\
\hline F7 & $0.42 \pm 0.05$ & $0.54 \pm 0.02$ & $16.00 \pm 0.06$ & $1.19 \pm 0.02$ & $21.15 \pm 0.05$ \\
\hline F8 & $0.51 \pm 0.08$ & $0.56 \pm 0.05$ & $8.93 \pm 0.04$ & $1.10 \pm 0.01$ & $19.56 \pm 0.04$ \\
\hline F9 & $0.52 \pm 0.02$ & $0.58 \pm 0.04$ & $10.34 \pm 0.05$ & $1.12 \pm 0.01$ & $18.75 \pm 0.03$ \\
\hline F11 & $0.47 \pm 0.04$ & $0.54 \pm 0.02$ & $12.96 \pm 0.05$ & $1.15 \pm 0.01$ & $17.84 \pm 0.03$ \\
\hline F12 & $0.58 \pm 0.03$ & $0.65 \pm 0.03$ & $10.77 \pm 0.02$ & $1.12 \pm 0.01$ & $19.29 \pm 0.05$ \\
\hline F13 & $0.49 \pm 0.04$ & $0.58 \pm 0.08$ & $15.52 \pm 0.03$ & $1.18 \pm 0.02$ & $22.14 \pm 0.08$ \\
\hline F14 & $0.47 \pm 0.05$ & $0.54 \pm 0.08$ & $12.96 \pm 0.04$ & $1.15 \pm 0.02$ & $21.04 \pm 0.07$ \\
\hline F15 & $0.48 \pm 0.06$ & $0.59 \pm 0.07$ & $18.64 \pm 0.02$ & $1.23 \pm 0.01$ & $18.56 \pm 0.05$ \\
\hline F16 & $0.58 \pm 0.05$ & $0.64 \pm 0.05$ & $9.38 \pm 0.03$ & $1.10 \pm 0.01$ & $17.45 \pm 0.06$ \\
\hline F17 & $0.48 \pm 0.04$ & $0.53 \pm 0.06$ & $9.43 \pm 0.05$ & $1.10 \pm 0.02$ & $16.84 \pm 0.04$ \\
\hline F18 & $0.43 \pm 0.03$ & $0.49 \pm 0.04$ & $12.24 \pm 0.06$ & $1.14 \pm 0.01$ & $19.84 \pm 0.06$ \\
\hline F19 & $0.46 \pm 0.07$ & $0.52 \pm 0.07$ & $11.54 \pm 0.02$ & $1.13 \pm 0.01$ & $21.54 \pm 0.04$ \\
\hline
\end{tabular}




\section{Post Compression Parameters Evaluation}

\section{- Weight variation}

Weight variation results of Formulations F1-F19 showed in table 2. So, it was predicted that all the formulation exhibited uniform weight with low standard deviation values within the acceptable variation as per IP.

\section{- Thickness}

Thickness of Formulations F1-F19 showed in table 2. No any major difference observed in formulation batches

\section{- Hardness}

It was observed that all the formulation has a good hardness and increase in polymer amount will increase the hardness of tablet. All Formulations have good strength to withstand the mechanical shocks.

\section{- $\quad$ Friability}

All formulation has a friability value less than $1 \%$, so this shows the durability of the prepared tablets.

\section{- Drug Content}

Formulations F1-F19 results of Drug Content found within the limit. No any deviation observed.

\section{- Swelling Index}

Water Intake ratio or swelling index of Formulations F1F19 results are given in table 3 shows that all formulations has a good swelling capacity so it's good for a floating

\section{- Floating Lag time and Total floating time}

All the formulations have floating time within $1 \mathrm{~min}$. so it is as per our requirement for floating tablet. Also, the total floating time is up to $12 \mathrm{hr}$. for all formulations.

\section{In Vitro Drug Release Study}

In vitro drug release study results are given in table 4 . Results shows that low amount of polymer in tablet does not release drug up to $12 \mathrm{hr}$ at starting. As we can see that in F1-F5, amount of polymer in tablet was just $25 \mathrm{mg}$. due to this F1-F5 does not give release up to $12 \mathrm{hr}$ and release observed up to $8 \mathrm{hr}$ only. After increasing the amount of polymer in formulation F6-F10 give the sustained effect up to $10 \mathrm{hr}$. so again amount of polymer increased to achieve desired release up to $12 \mathrm{hr}$ and finally F11-F19 gives release up to $12 \mathrm{hrs}$. But here objective not achieved because in 12-hour maximum drug should be release. Results shown that after increasing polymer amount up to $75 \mathrm{mg}$ in single polymer more than $95 \%$ drug release not achieved in $12 \mathrm{hr}$. also the floating lag time was observed more than 1 min in F1-F20 formulation. Further trials taken with a combination of two polymers.

Table 2: Post Compression Parameters of Formulation F1-F19

\begin{tabular}{|c|c|c|c|c|}
\hline Formulation & $\begin{array}{c}\text { Weight variation } \\
\mathbf{( m g )}(\mathbf{n = 1 0})\end{array}$ & $\begin{array}{c}\text { Thickness(mm) } \\
\mathbf{( n = 3 )}\end{array}$ & $\begin{array}{c}\text { Hardness } \\
\left(\mathbf{K g} / \mathbf{c m}^{\mathbf{2}} \mathbf{( n = 3}\right)\end{array}$ & Friability (\%) \\
\hline F1 & $301 \pm 1.5$ & $5.51 \pm 0.09$ & $5.13 \pm 0.15$ & 0.48 \\
\hline F2 & $300 \pm 1.4$ & $5.59 \pm 0.11$ & $4.72 \pm 0.07$ & 0.70 \\
\hline F3 & $302 \pm 1.5$ & $5.50 \pm 0.12$ & $5.26 \pm 0.22$ & 0.36 \\
\hline F4 & $299 \pm 1.6$ & $5.52 \pm 0.11$ & $5.13 \pm 0.15$ & 0.49 \\
\hline F6 & $298 \pm 1.7$ & $5.51 \pm 0.11$ & $5.15 \pm 0.15$ & 0.50 \\
\hline F7 & $300 \pm 1.8$ & $5.48 \pm 0.13$ & $4.76 \pm 0.17$ & 0.68 \\
\hline F9 & $301 \pm 1.5$ & $5.52 \pm 0.14$ & $5.16 \pm 0.13$ & 0.57 \\
\hline F10 & $298 \pm 1.4$ & $5.51 \pm 0.12$ & $5.19 \pm 0.11$ & 0.52 \\
\hline F11 & $299 \pm 1.4$ & $5.51 \pm 0.10$ & $5.15 \pm 0.06$ & 0.59 \\
\hline F12 & $301 \pm 1.5$ & $5.50 \pm 0.13$ & $5.29 \pm 0.13$ & 0.50 \\
\hline F13 & $300 \pm 1.6$ & $5.49 \pm 0.14$ & $4.76 \pm 0.11$ & 0.41 \\
\hline F14 & $301 \pm 1.7$ & $5.47 \pm 0.08$ & $5.08 \pm 0.11$ & 0.59 \\
\hline F15 & $302 \pm 1.8$ & $5.51 \pm 0.09$ & $5.23 \pm 0.12$ & 0.54 \\
\hline F16 & $298 \pm 1.7$ & $5.48 \pm 0.11$ & $4.86 \pm 0.15$ & 0.49 \\
\hline F17 & $299 \pm 1.8$ & $5.47 \pm 0.06$ & $5.06 \pm 0.17$ & 0.60 \\
\hline F18 & $302 \pm 1.6$ & $5.49 \pm 0.11$ & $4.75 \pm 0.14$ & 0.81 \\
\hline & $303 \pm 1.7$ & $5.52 \pm 0.14$ & $5.41 \pm 0.10$ & 0.42 \\
\hline $\mathbf{3 0 1 9}$ & $302 \pm 1.4$ & $5.50 \pm 0.15$ & $5.13 \pm 0.09$ & 0.45 \\
\hline
\end{tabular}


Table 3: Post Compression Parameters of Formulation F1-F19

\begin{tabular}{|c|c|c|c|c|}
\hline Formulation & $\begin{array}{c}\text { Drug Content } \\
\mathbf{( \% )}(\mathbf{n}=\mathbf{3})\end{array}$ & $\begin{array}{c}\text { Swelling Index } \\
\mathbf{( \% )}(\mathbf{n = 3})\end{array}$ & $\begin{array}{c}\text { Floating Lag Time(sec) } \\
\mathbf{( n = 3 )}\end{array}$ & $\begin{array}{c}\text { Total Floating Time } \\
\mathbf{( h r} \text { ) }\end{array}$ \\
\hline F1 $\mathbf{n = 3})$
\end{tabular}

In combination batches F16-F19, batch F18 gives maximum $\%$ drug release $99.7 \%$ in $12 \mathrm{hr}$. also the floating lag time observed 32 seconds which was lowest in all formulations. Also, total floating time was $12 \mathrm{hr}$ so main floating parameters of floating tablets fulfill by combination of Carbopol 934 and Polyox N-60K. So the best combination of polymer based on \% drug release, floating time and total floating was F18 which contains Carbopol 934 and Polyox $\mathrm{N}-60$ Kboth $50 \mathrm{mg}$. Initially trials were taken with single polymer. In single polymer trials, Carbopol 934 and Polyox $\mathrm{N}-60 \mathrm{~K}$ gives good, sustained effect up to $12 \mathrm{hr}$ so based on that, combination of polymer tried and both polymers in combination give max \% drug release of $99.7 \%$. So F18 formulation finalized as optimized formulation.

Table 4: \% Drug release study of Formulation F1-F19

\begin{tabular}{|c|c|c|c|c|c|c|c|c|}
\hline Code & \multicolumn{7}{|c|}{ \% Drug Release } \\
\hline F1 & $\mathbf{1}$ & $\mathbf{2}$ & $\mathbf{3}$ & $\mathbf{4}$ & $\mathbf{6}$ & $\mathbf{8}$ & $\mathbf{1 0}$ & $\mathbf{1 2}$ \\
\hline F2 & $36.8 \pm 0.1$ & $45.7 \pm 0.2$ & $68.9 \pm 0.1$ & $84.4 \pm 0.5$ & $89.4 \pm 0.3$ & $98.6 \pm 0.8$ & - & - \\
\hline F3 & $45.8 \pm 0.5$ & $59.7 \pm 0.4$ & $69.7 \pm 0.4$ & $89.4 \pm 0.5$ & $95.4 \pm 0.4$ & $99.8 \pm 0.7$ & - & - \\
\hline F4 & $52.4 \pm 0.7$ & $74.5 \pm 0.5$ & $81.6 \pm 0.7$ & $94.5 \pm 0.7$ & $97.8 \pm 0.3$ & $98.9 \pm 0.2$ & - & - \\
\hline F5 & $39.8 \pm 0.8$ & $48.7 \pm 0.6$ & $66.4 \pm 0.8$ & $79.9 \pm 0.8$ & $89.4 \pm 0.2$ & $99.1 \pm 0.7$ & - & - \\
\hline F6 & $25.5 \pm 0.7$ & $39.4 \pm 0.4$ & $49.7 \pm 0.3$ & $75.4 \pm 0.9$ & $81.5 \pm 0.7$ & $88.7 \pm 0.8$ & $99.5 \pm 0.2$ & - \\
\hline F7 & $30.4 \pm 0.7$ & $45.8 \pm 0.7$ & $65.4 \pm 0.4$ & $79.4 \pm 0.4$ & $81.4 \pm 0.6$ & $94.5 \pm 0.6$ & $98.7 \pm 0.1$ & - \\
\hline F9 & $32.1 \pm 0.5$ & $46.1 \pm 0.2$ & $65.4 \pm 0.5$ & $74.8 \pm 0.5$ & $87.4 \pm 0.5$ & $95.6 \pm 0.5$ & $99.4 \pm 0.2$ & - \\
\hline F10 & $45.6 \pm 0.3$ & $68.4 \pm 0.5$ & $74.8 \pm 0.8$ & $81.4 \pm 0.3$ & $84.5 \pm 0.3$ & $91.9 \pm 0.3$ & $98.7 \pm 0.2$ & - \\
\hline F11 & $29.4 \pm 0.4$ & $41.2 \pm 0.2$ & $59.4 \pm 0.7$ & $72.1 \pm 0.1$ & $84.5 \pm 0.2$ & $89.1 \pm 0.7$ & $99.8 \pm 0.7$ & - \\
\hline F12 & $27.5 \pm 0.2$ & $35.6 \pm 0.6$ & $40.5 \pm 0.9$ & $58.9 \pm 0.2$ & $75.1 \pm 0.5$ & $80.7 \pm 0.2$ & $84.9 \pm 0.8$ & $91.6 \pm 0.6$ \\
\hline F13 & $8.4 \pm 0.4$ & $18.6 \pm 0.7$ & $20.8 \pm 0.7$ & $36.7 \pm 0.5$ & $48.9 \pm 0.3$ & $74.4 \pm 0.4$ & $79.4 \pm 0.3$ & $81.2 \pm 0.5$ \\
\hline F15 & $11.8 \pm 0.8$ & $17.8 \pm 0.8$ & $22.7 \pm 0.8$ & $29.9 \pm 0.6$ & $38.4 \pm 0.5$ & $49.4 \pm 0.6$ & $69.7 \pm 0.1$ & $78.4 \pm 0.8$ \\
\hline F16 & $20.4 \pm 0.2$ & $39.7 \pm 0.2$ & $64.7 \pm 0.3$ & $78.0 \pm 0.2$ & $87.9 \pm 0.2$ & $89.4 \pm 0.2$ & $91.7 \pm 0.7$ & $92.4 \pm 0.7$ \\
\hline F17 & $24.1 \pm 0.5$ & $32.5 \pm 0.4$ & $39.4 \pm 0.5$ & $45.7 \pm 0.5$ & $74.7 \pm 0.7$ & $79.8 \pm 0.8$ & $85.2 \pm 0.6$ & $90.2 \pm 0.5$ \\
\hline F18 & $33.5 \pm 0.3$ & $39.2 \pm 0.8$ & $45.5 \pm 0.3$ & $48.7 \pm 0.5$ & $64.7 \pm 0.2$ & $75.4 \pm 0.6$ & $88.9 \pm 0.5$ & $99.7 \pm 0.2$ \\
\hline F19 & $29.4 \pm 0.6$ & $60.1 \pm 0.7$ & $65.8 \pm 0.2$ & $69.4 \pm 0.8$ & $75.4 \pm 0.4$ & $78.9 \pm 0.6$ & $80.5 \pm 0.5$ & $82.7 \pm 0.5$ \\
\hline & & & & & & & - \\
\hline
\end{tabular}




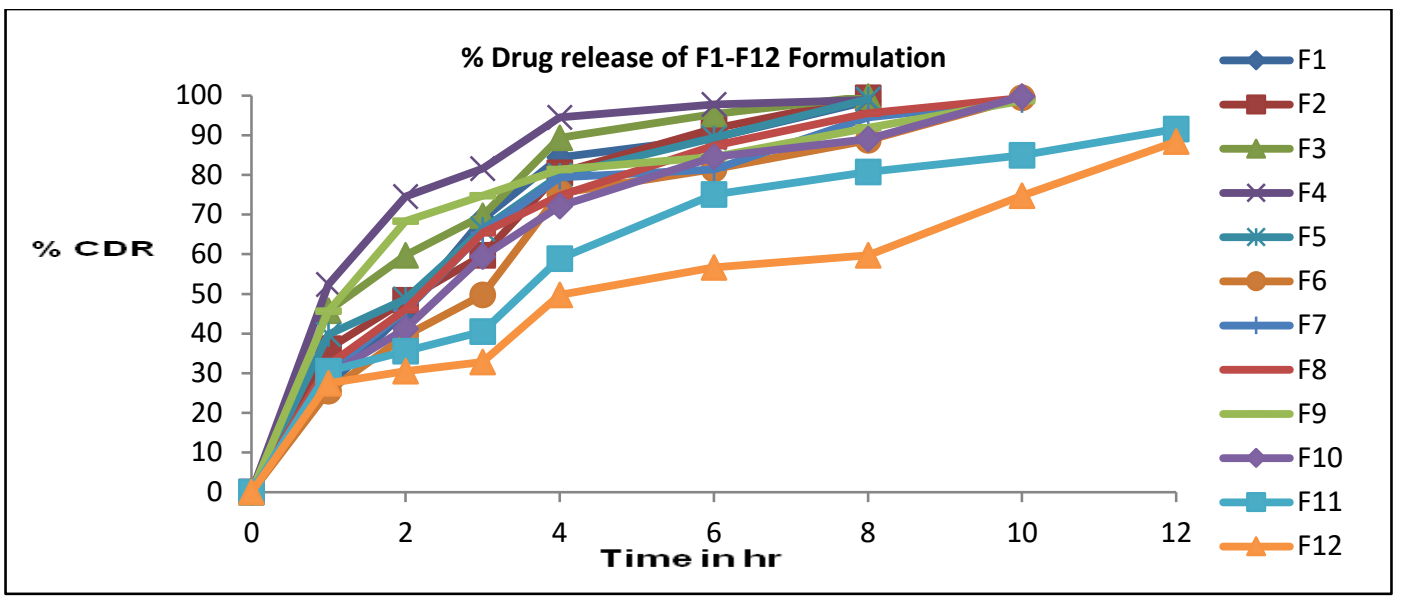

Figure 1: Comparison of \% Drug release of Formulation F1-F12

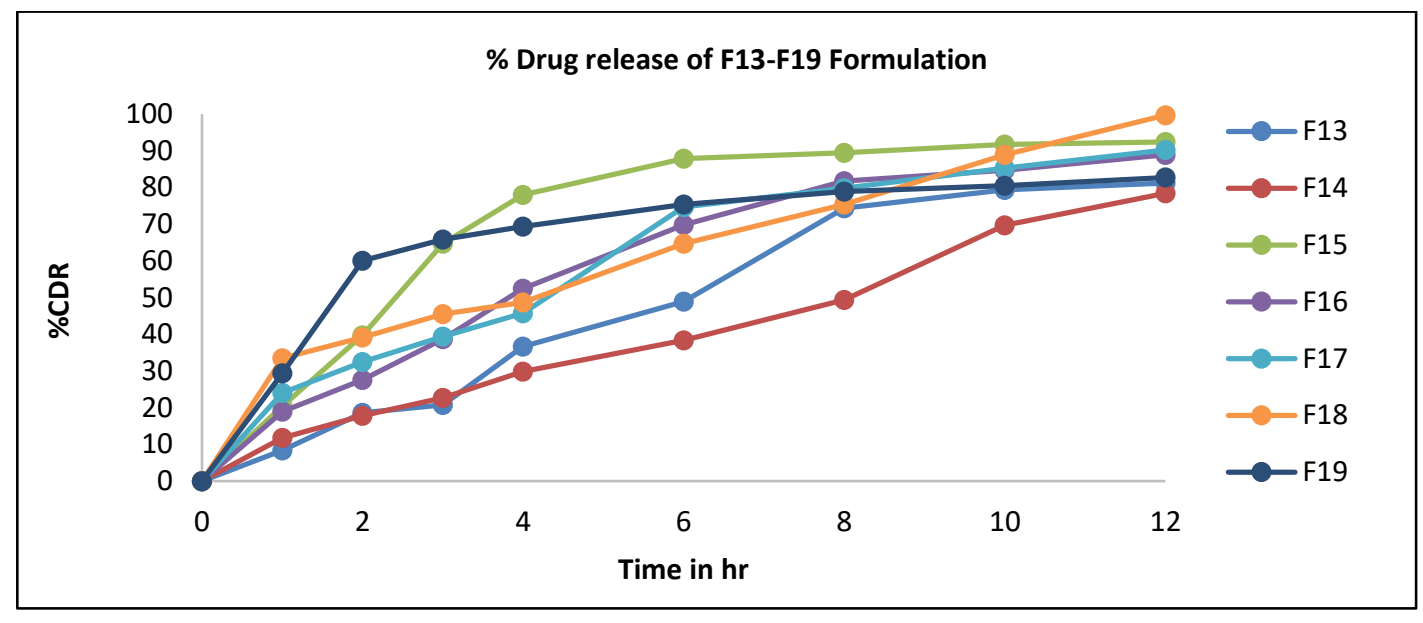

Figure 2: Comparison of \% Drug release of Formulation F13-F19

\section{Drug release kinetic study}

The drug release data of the final batch F18 was fitted in to different kinetic models. Among all, the best fitted model explained by Higuchi model because $\mathrm{R}^{2}$ value of Higuchi model has 0.984 shown in table 5 .

Table 5: Kinetic modeling data of batch F18

\begin{tabular}{|c|c|c|}
\hline Kinetic Model & Parameters & Value \\
\hline Zero Order & $\mathrm{R}^{2}$ & 0.932 \\
\hline First Order & $\mathrm{R}^{2}$ & 0.730 \\
\hline Higuchi & $\mathbf{R}^{2}$ & $\mathbf{0 . 9 8 4}$ \\
\hline Korsmeyer-Peppas & $\mathrm{R}^{2}$ & 0.527 \\
\hline Hixon Crowell & $\mathrm{R}^{2}$ & 0.910 \\
\hline
\end{tabular}

Higuchi model was found to best describe the $\mathrm{R}^{2}$ (coefficient of determination). Korsmeyer-Peppas equation also best suits the dissolution data where the values of " $n$ " were $0.45-0.89$ indicating anomalous, nonFickian, or nearly zero-order release mechanism. Drug release mechanism from prepared floating tablets of F18 batch was elucidated by fitting the in vitro dissolution data in Korsmeyer-Peppas equation. The value of " $n$ " for the optimized formulation was greater than 0.45 indicating non-Fickian case II transport mechanism.

\section{Stability Study}

Stability study of optimized batch F18 performed for 1 month at $40{ }^{\circ} \mathrm{C} / 75 \% \mathrm{RH}$ and evaluated for various parameters from the stability study data, it revealed that the formulation $\mathrm{F} 18$ stable at $40{ }^{\circ} \mathrm{C} / 75 \% \mathrm{RH}$ condition. Results are well within acceptable limits.

\section{CONCLUSION}

Review of literature reveals that floating drug delivery systems are easiest approach for technical and logical point of view among gastro retentive drug delivery system, so for present study, floating drug delivery system was chosen to increase the gastric residence time of dosage form which led to increased bioavailability of various drug substances. Tofacitinib Citrate is the drug of choice for the treatment of moderate to severe rheumatoid arthritis. So, in present investigation, an attempt was made to deliver Tofacitinib Citrate via floating drug delivery system to the vicinity of absorption site by prolonging the gastric residence time of the dosage form. Tablets were subjected to various evaluation parameters such as hardness, friability, thickness, weight variation, drug content, floating property study, swelling study, in vitro drug release study. It was revealed that tablets of all batches had acceptable physical parameters. The effervescentbased gastro retentive drug delivery is a promising 
approach to achieve in vitro buoyancy by using gel-forming polymer HPMC K4M, HPMC K15M, HPMC K100M, Carbopol $934 \mathrm{P}$ and Polyox $\mathrm{N}-60 \mathrm{~K}$ and gas generating agent sodium bicarbonate. Fourier transform Infrared spectroscopy confirmed the absence of any drug/polymers/excipients interactions. The drug content of all the formulations was found to be in the range of $96.22 \%$ to $99.45 \%$, which indicates the uniform drug content. In vitro floatability studies revealed that most of the tablets still floated for more than 12 hours because of their low densities. In vitro drug release studies were performed for all the prepared formulations. All the prepared floating tablets exhibited good drug release. Amount of polymer in floating tablet plays an important role in drug release. Low amount of polymer in formulation doesn't make a tablet to release a drug up to $12 \mathrm{hr}$. Hence F18 formulation in combination of Polyox $\mathrm{N}-60 \mathrm{~K}$ and Carbopol $934 \mathrm{P}$ makes tablet float and release a drug up to $12 \mathrm{hr}$. The drug release data of formulation F18 fitted to different kinetic models and the best fitted model was Higuchi model. Stability study of formulation F18 was found satisfactory. Hence, F18 batch was optimized batch.

Acknowledgment: The Author and co-author, thanks to Saraswati Institute of Pharmaceutical Sciences, for providing the necessary facility to accomplish the work we also humble gratitude to our colleague and non-teaching staff for their support during the work.

\section{REFERENCES}

1. Pund AU, Shendge RS, Pote AK. Current Approaches on Gastroretentive Drug Delivery systems. J Drug Deliv Ther. 2020; 10(1): 139-46.
2. Tomar A, Department of Pharmaceutical Technology, Meerut Institute of Engineering and Technology (MIET), NH-58, DelhiRoorkee Highway, Meerut-250005, Uttar Pradesh, India, Upadhyay A, Gupta SK, Kumar S. An overview on gastroretentive drug delivery system: Current approaches and advancements. Curr Res Pharm Sci. 2019; 9(1): 12-6.

3. Tripathi J, Thapa P. Review on gastroretentive drug delivery systems. "Pharmaceutics. 2019; 11(4): 193.

4. More S, Gavali K, Doke O, Kasgawade P. GASTRORETENTIVE DRUG DELIVERY SYSTEM. J Drug Deliv Ther [Internet]. 2018; 8(4): Available from: http://dx.doi.org/10.22270/iddt.v8i4.1788.

5. Gunda R. Formulation Development and Evaluation of Gastro Retentive Drug Delivery Systems-A Review. "Journal of Pharmacy Research. 2017; 8(1): 11-20.

6. Chudiwal V, Shahi S, Chudiwal S, Ahale D. Innovative Technologies for Gastro-Retentive. "Asin Jrnl of Pharma Edu and Research. 2017; 6(4): 22-8.

7. Kanwar N, Kumar R, Sarwal A, Sinha VR. Preparation and evaluation of floating tablets of pregabalin. Drug Dev Ind Pharm. 2016; 42(4): 654-60.

8. Patil H, Tiwari R, Repka M. Advancements in bioadhesive floating drug delivery systems: A mini-review. "J Drug Deliv Sci Technology. 2016; 31: 65-71.

9. Ish G, Meenakshi M, Manish D. Floating Drug Delivery Systems: A Novel Approach. " Research J Pharm and Tech. 2015; 8(4): 490-495.

Source of Support: The author(s) received no financial support for the research, authorship, and/or publication of this article.

Conflict of Interest: The author(s) declared no potential conflicts of interest with respect to the research, authorship, and/or publication of this article.

For any question relates to this article, please reach us at: editor@globalresearchonline.net New manuscripts for publication can be submitted at: submit@globalresearchonline.net and submit_ijpsrr@rediffmail.com 